\title{
What Makes a Woman? Case Studies Documenting The Reasons for and Circumstances of Female Genital Mutilation/Cutting in Indonesia, Ethiopia and Kenya
}

Tasneem Kakal ( $\nabla$ tasneem.kakal@gmail.com )

KIT Royal Tropical Institute https://orcid.org/0000-0002-8845-0465

Irwan Hidayana

University of Indonesia: Universitas Indonesia

\section{Berhanu Abeje}

Addis Ababa University

Tabither Gitau

Independent Consultant

Maryse Kok

KIT Royal Tropical Institute

Anke van der Kwaak

KIT Royal Tropical Institute

\section{Research}

Keywords: female genital cutting, female genital mutilation, Indonesia, Kenya, Ethiopia, gender, body

Posted Date: August 13th, 2021

DOI: https://doi.org/10.21203/rs.3.rs-786579/v1

License: (ㄷ) (i) This work is licensed under a Creative Commons Attribution 4.0 International License. Read Full License 


\section{Abstract}

Background: Female genital cutting/mutilation is a harmful traditional practice that violates women's rights and has adverse health consequences. This paper presents the reasons for and circumstances of female genital mutilation/ cutting (FGM/C) in specific settings of three countries - Indonesia, Ethiopia and Kenya.

Methods: Data were collected through a household survey with young people (15-24 years) and through focus group discussions, in-depth interviews and key informant interviews with youth and community stakeholders in 2016 and 2017. Descriptive statistics and thematic content analysis were conducted.

Results: The study findings confirm some of the reasons for FGM/C documented by previous studies, noting that these reasons are strongly interconnected, and gender norms are the underlying driver. In all three settings, these reasons drive the alterations of female bodies to result in a 'cultured' body that is acceptable to the patriarchal status quo. This results in the 'pure body' in Indonesia, the 'tame' body in Ethiopia and the 'adult body' in Kenya. Health workers and parents play an important role in decision-making around FGM/C in all settings. In Kenya, in particular, young women negotiate their role in decision-making around FGM/C as they are older at the time of circumcision. The study reveals how the changing legal and social contexts in each setting bring about changes in the tradition of FGM/C resulting in medicalization of FGM/C in Indonesia, a lowered age of cutting for girls in Kenya and the increasingly underground practice of FGM/C in Ethiopia.

Conclusions: The three cases demonstrate the huge variation in the practice of $\mathrm{FGM} / \mathrm{C}$ and the social meaning attributed to it by young women and their communities. There is a need to further explore the role of parents in decision-making. Due to the links between the different drivers of FGM/C within each context, the study concludes that context-specific strategies need to be adopted by interventions to create long-lasting change.

\section{Plain English Summary}

Female genital cutting/mutilation (FGM/C), a harmful traditional practice that violates the rights of women, continues to be practiced in Asia and Africa. This paper presents the reasons for and circumstances of FGM/C in specific settings of three countries - Indonesia, Ethiopia and Kenya. We interviewed young people (15-24 years) and community members individually and in groups to understand the practice of FGM/C and its causes in 2016 and 2017. We also surveyed young people (15-24 years). We found that there are many different reasons in each setting for $\mathrm{FGM} / \mathrm{C}$ and there is variety in how the practice is done. These reasons are motivated by discriminatory ideas about gender, which dictate the differences between women and men, and the roles they should play. For these reasons, women's bodies are physically changed so that they can become accepted by the culture of the community. Health workers, parents and in the case of Kenya young women, all play a role in deciding if and when the FGM/C should take place. Due to the differences in the practices and reasons per settings, the study concludes that efforts to tackle FGM/C should be suited to the context.

\section{Background}

Female Genital Mutilation (FGM) also known as Female Genital Cutting (FGC) or Female Circumcision (FC), includes any partial or total excision of external female genitalia for non-medical /non-therapeutic purposes (WHO 2018). It is a harmful traditional practice that is widely practiced in Sub-Saharan Africa and parts of Asia. The cited benefits for the practice of FGM/C include psychosexual reasons that aim to limit the sexual desire of women and maintain their virginity, sociological reasons which include initiation rites, hygiene and aesthetic reasons, myths about enhancement of fertility and religious reasons(1). In a systematic review conducted by Berg \& Denison on exile communities in Western countries, six factors were revealed to perpetuate FGM/C: cultural tradition, sexual morals, marriageability, religion, health benefits, and male sexual enjoyment (2). The convention theory (3) remains popular and relevant to explain that FGM/C is a self-enforcing convention where individuals make choices based on local ideas of gender, honour and sexuality and that their choices are reinforced on the basis of rewards they gain in conforming to the norm. This study presents three case studies outlining the 
reasons for and circumstances of FGM/C in the Sundanese and Sasak communities in Indonesia, the Amahara community in Ethiopia and the Maasai community in Kenya. In this study, we use the combined term of FGM/C. When citing literature, we use the term used by the author(s).

FGM/C in Indonesia has seen a course of medicalization. It progressed from an initial ban imposed by the government in 2006, to allowing the practice if done by health providers in 2010 due to a fatwa issued by the Indonesian Ulema Council (Majelis Ulama Indonesia) in 2008. This fatwa stated that FGM/C was considered a rule of Islam and the membrane covering the clitoris should be removed. In 2014, this law of 2010 was repealed (4). However, medicalized FGM/C still continues. International agencies have strongly condemned such medicalization, citing research that found that medicalization has led to more skin being removed by health providers using scissors as opposed to a prick by traditional circumcisers $(5,6)$. Almost half of the girls under the age of 12 have undergone some form of FGM/C in Indonesia, mostly between the ages of 1-5 months (4). In a recent study, Type 4, Type 1 and symbolic methods were most commonly found in seven regions (7). Closely linked to Islamic teachings (8), with the advent of Western medicine, the discourse for FGM/C shifted to hygiene (9). Religious discourse, medicalization and cultural preservation perpetuate the practice.

In Ethiopia, the type of FGM/C differs by ethnic group, and therefore the reasons motivating the practice also vary (10). FGM/C can be practiced as a pre-requisite to marriage or childbirth, to control sexual desire of women, as a marker of cultural identity, as part of a puberty rite, for religious reasons, social acceptance, hygiene, and to safeguard a woman's virginity (11-15). The Ethiopian government declared FGM/C as a Harmful Traditional Practice, criminalized the practice in 2006 and is taking efforts to eradicate it. In the Amhara region, according to the 2005 Demographic Health Survey, $68.5 \%$ of women reported to have undergone FGM/C while according to the EGLDAM in 2007, 78\% from the region reported the same, with a majority reporting Type 1 (11). Usually carried out on the eighth day after birth, though varies by type of FGM and by region, it is believed to aid childbirth, and is seen as a requisite to early marriage $(11,13)$. Some evidence of the belief that an uncircumcised woman has a higher sexual desire and hence is sexually incompatible with her husband exists (11).

In Kenya, the rate of FGM/C varies. While the overall rate of FGM/C stands at $27 \%$, some regions such as the North East witness a rate of $98 \%$. The Kenyan government has banned the practice in 2011 with the passing of the 'Prohibition of Female Genital Mutilation Act'. According to the Demographic Health Survey (DHS) (2014), 78\% of the Maasai were circumcised (16). Of these women, $92 \%$ stated they had been cut and some flesh was removed by a traditional circumciser. The DHS also indicates that the age at circumcision is going down and more than half of Maasai women sampled reported to have been circumcised between 10 and 14 years. For the Maasai, religion does not feature as a reason for practicing FGM (16). Rather, FGM/C constitutes the rite of passage or initiation ceremony from childhood to adulthood and plays an important role in defining women's roles and identity including that of being a wife and mother (17). However according to the DHS 2014, the majority of the Maasai women sampled did not find that it was a requirement for the community and thought that it should not continue, perhaps indicating changing norms.

\section{Methodology}

The mixed methods study was part of the Yes I Do (YID) programme. Data were collected between July 2016 and September 2016 in all countries. In Ethiopia, there was an interruption in the data collection and a part of the data were collected in July-August 2017.

\section{The study context}

Baseline studies in West Lombok and Sukabumi districts in Indonesia, Bahir Dar and Qewet woredas or districts in Ethiopia and Kajiado County (West and Central) in Kenya as part of the Yes I Do programme (2016-2020) aimed at reducing child marriage, teenage pregnancy and FGM/C. 


\section{Study methods}

Qualitative data were collected using purposive sampling. Focus group discussions (FGDs) were held with young women and young men (15-24 years) separately and parents or caregivers and chiefs (only in Kenya). In-depth interviews (IDIs) were conducted with young people, parents or caregivers, traditional or religious leaders, elderly women - some of whom were (former) circumcisers, teachers, health and social workers and community-based organization (CBO) or youth organization staff. Key informant interviews (KIls) were conducted with district level and NGO staff.

A two-stage cluster household survey was also carried out in all three country settings where youth between 15-24 years were randomly sampled. Sample size calculations resulted in a sample size of 1602 respondents in Ethiopia, 1534 respondents in Indonesia and 1368 respondents in Kenya. The ratio of women to men in the sample was 75:25. Data were collected in 2016 in Indonesia and Kenya. In Ethiopia, data were collected in two stages - in 2016 and 2017 due to the political insecurity in the country leading to challenges in completing data collection. An overview of the sampling calculations, methods and participants is presented in additional file 1. An overview of demographic characteristics of study respondents and participants is presented in additional file 2 .

Quantitative data were collected using ODK Collect on tablets and analyzed using Stata, while qualitative data were recorded and analyzed using NVivo. Descriptive statistics are presented in the paper. The qualitative and quantitative methods gave insight into the trends, the practice and the perceptions of youth and other stakeholders on FGM/C.

This paper presents the three settings as separate case studies, outlining a description of the act, the reasons for and the decision-making process of FGM/C. A case study approach can capture the nuances and context-specific nature of FGM/C.

\section{Ethical considerations}

Informed written consent was taken from all study participants. In the case of minors, consent was obtained from parents or caregivers, and assent from the child. Approval was also taken at different administrative levels. Ethical approval was granted from the KIT Royal Tropical Research Ethics Committee and the Research Ethics Committee of the Faculty of Public Health, University of Indonesia, Ethical Review Committee of the Amhara Region Public Health Institute in Ethiopia and the African Medical and Research Foundation (AMREF) in Kenya.

\section{Limitations}

Limitations include the possible social desirability of answers. In the survey, in particular, there may have been an underestimation of figures, particularly because of the sensitive nature of the topic considering that FGM/C is illegal in Ethiopia and Kenya. However, in the context of FGDs, there may have been an over-estimation due to the socially sanctioned benefits of 'appearing' to be circumcised. Since the data were collected in the local languages Maasai, Indonesian, Sundanese and Sasak, and Amharic, translations may not have been able to capture all nuances.

\section{Results}

\section{Case Study - Indonesia}

\section{The act of FGM/C}

FGM/C was known as coke, koet, dicongke/ which meant 'to scoop out' in Sukabumi and 'tesucl or 'tesucian' which meant 'to sanctify the female genital' in West Lombok. Most youth knew about FGM/C. In Sukabumi, 92\% of women reported to have undergone FGM/C, while 53\% reported the same in West Lombok. In many cases, young women did not know if they were circumcised. Many circumcised young women did not know which type of FGM/C they had undergone, as they were circumcised between 30 and 40 days after birth. They described the process of FGM/C in various ways, which could indicate either a lack of knowledge or diversity in the ways of circumcising. According to a key informant, the act of circumcision was simply a formality with almost no bleeding involved. 
Traditionally, FGM/C was carried out by a traditional birth attendant (TBA) known as the paraji, mak beurang or belian. However, the introduction of the law in 2010 only sanctioned health care workers to do so. Although this law was eventually repealed, many parents mentioned going to the midwife, nurse or doctor. However, as per young women (FGD, 20-24) and parents (FGD), midwifes often refused to conduct FGM/C. Despite the law, as per our findings, some TBAs and a few midwives still conducted FGM/C.

The circumcisers explained that the process of circumcision in Sukabumi was carried out by 'nicking'. This nicking of the woman's clitoral hood was done using a knife or a needle until some liquid or blood was shed. This was either done by a paraji or by a mak beurang, usually at an average age of 40 days. In West Lombok, FGM/C involved the use two colonial Dutch coins called sekepeng to rub the clitoris, usually at the age of one week to a month. In many cases, young women did not know when they were circumcised. Prayers were said upon washing the genital, after which the 'dark' part was removed, using a razor blade or coins which could at times cause bleeding. If a blade was used, it was simply to 'leave a mark' or at times make a small cut. Other items used included a glass of water, rice, flower, betel leaf and nut.

\section{Reasons for FGM/C}

Young people including males and females indicated that circumcision was carried out with the purpose of 'removing the excrement' or najis i.e. impurities. Young people, particularly men in West Lombok, shared that this would ensure cleanliness. Women were perceived to have more najis than men. According to a parent in Sukabumi, if not removed, 'the part' would become filthy. FGM/C was referred to as 'purification' or 'sanctification' by some parents and a traditional midwife in West Lombok who explained that this did not involve any cutting. One young woman (FGD, 20-24 years) shared that female circumcision could 'save the woman' from diseases, a reasoning commonly shared by male participants for male circumcision. A young woman (FGD, 20-24 years) mentioned that the lips of the vagina should not be too big and hence circumcision was important.

Across young people and all stakeholders in both districts, there was mention of circumcision being an 'obligation' in Islam or 'sunnah'i.e. recommended and its absence being 'haram'. According to our survey results, $74 \%$ of all young women and $68 \%$ of young men indicated that their religion recommended FGM/C. Despite strong religious motivations, when young men in Sukabumi and a key informant were asked about which verses in the Quran mentioned this, they were not aware. A young woman (FGD, 20-24 years) mentioned that non-Muslims also got circumcised, however, a TBA in Sukabumi shared that it was likely only the Muslims who got circumcised.

Another motivation was the control of sexual desire, lust and sexual performance, a perspective particularly prevalent in Sukabumi. Uncircumcised women were associated with being horny, being hypersexual and having a bigger sexual drive than men in both districts by women and men, youth as well as adults. The term 'coquettish' was often used by young women and a midwife from West Lombok and a TBA from Sukabumi to describe women who were not circumcised. In both districts, there was a common Islamic belief, particularly among young men, that the desire of a woman is nine times that of the man and FGM/C is a means to correct for this.

Marriageability did not factor in as a major driver of FGM/C. As per the survey data, young men preferred circumcised partners to a much greater extent - despite not knowing any specific advantages or reasons of the practice - in Sukabumi than in West Lombok. Most participants did not mention any negative consequences of FGM/C. This was confirmed by the survey results where the majority of young people did not think that FGM/C caused menstrual, sexual, fertility or labourrelated problems.

"The girls have been circumcised since a long time ago, according to the religion it must be cut off. If it is not discarded, it becomes filthy.... The desire (...) the concern was to control the desire. If a girl is not circumcised, she would be unstoppable."-Parent, FGD (Sukabumi), Indonesia 


\section{Decision-making}

Decision-making regarding FGM/C laid with the parents who were influenced by the willingness of the circumciser or health worker they had approached. The extended family and the community were influential in the decision-making process and mothers were held accountable if their daughters had not been circumcised.

According to a health office staff member in Sukabumi,, there were instructions from the national medical accrediting body and health ministry that FGM/C was not allowed. Parents in an FGD as well as two young women (FGD, 20-24 years) cited that they would continue to circumcise their daughters as they had gone through it. The TBA and the midwife explained that it was illegal and there were many cases where if the health worker or TBA refused, it was not done. However, the decision-making process seemed to be negotiated by health workers with parents. One nurse mentioned that if parents really wanted their daughter to be circumcised, the nurses pretended to do so or rubbed cotton and told the parents that they had performed FGM/C. On the other hand, although a midwife in West Lombok opposed FGM/C, she neither actively prohibited or supported it in her practice. The TBA (in Sukabumi) mentioned that although she would not break the law, she would make an exception and carry out the FGM/C when parents had traveled from far.

\section{Case Study - Ethiopia}

\section{The act of FGM/C}

In Bahir Dar and Qewet, many young women in the FGDs, a young man in an IDI and many key informants expressed that FGM/C was 'still' practiced, albeit in a secretive and hidden way. There was a mixed opinion regarding its prevalence. The survey found that while $22 \%$ of young women did not know whether they had been circumcised, $54 \%$ reported being cut. However, three-quarters of these women did not know what type of circumcision was done or who had carried it out. Many simply explained that it involved 'cutting part of the clitoris'. This lack of knowledge could be explained by the fact that FGM/C took place seven days after birth. A young woman (FGD) and a key informant explained that the likelihood of $\mathrm{FGM} / \mathrm{C}$ fell after this day and decreased further after two years of birth.

A young woman (FGD, 15-20 years) shared that uncircumcised young women could be cut at the time of marriage. This was reiterated by young women (FGD, 15-20 years) who shared that private health professionals circumcised girls or young women after marriage if they were not circumcised earlier. According to a young woman in the same FGD, circumcisers were elderly women. Due to FGM/C being declared illegal, different strategies were used to carry it out. A young man (IDI, 24 years) shared that circumcisers came from outside the community to maintain anonymity and evade law officials. However, as explained by a key informant, bringing circumcisers from outside the village was an expensive affair and hence acted as a deterrent towards parents.

Although FGM/C was hidden, it was often accompanied by a ceremony including coffee and porridge. At times, according to a key informant, parents facilitated the FGM/C of their daughter under the pretext of male circumcision - either pretending they have sons or having the FGM/C accompanied by male circumcision. In other cases, it would be under the pretext of a simple social gathering, as mentioned by another key informant. Others took their daughters to remote gottes (villages) or to relatives to hide and circumcise their daughter, as explained by a young woman (FGD).

\section{Reasons for FGM/C}

The community, including youth, believed that FGM/C was practiced to ensure that a young woman was able to find a good husband in the future. According to a young man (FGD, 15-18 years) and two key informants, an uncircumcised woman was perceived by the community as being disobedient and aggressive towards her husband. There were accounts of women being returned by their husbands if they were found to be uncircumcised, as related by a few young women. A young woman (FGD, 18-24 years) shared an account of a husband divorcing his wife as she was not circumcised. Similar cases were reiterated by some other young women and a key informant. 
"... no parents would be willing to face the humiliation of their daughter returned to her parents after marriage when the husband finds that she is not circumcised."- Key informant, Bahir Dar

Although there seems to be a clear link between FGM/C and marriage, our survey results found that most young men did not know whether they preferred a circumcised partner or not.

Most participants including parents, key informants and young people frequently mentioned that FGM/C was perceived to shape a woman's sexual desire and performance. These revolved around a number of beliefs - some were about the anatomy of the vagina and the clitoris, and others were around sexual satisfaction. As indicated by many young women, key informants and male parents, it was commonly believed that husbands faced difficulty with penetration with an uncircumcised woman and that she would not feel satisfied easily. A young woman (IDI, 16 years) also mentioned that, if uncircumcised, a woman would not be able to feel emotions during sex, while other participants such as a grandmother and a few key informants mentioned that she would have a higher sexual drive than a man.

"On the other hand, failure of circumcision might contribute to, according to local traditions and widely held cultural beliefs, (1) complication during child delivery, (2) girls being aggressive towards their husbands, not willing to accept orders/demands of husbands and not submissive and are not good wives, (3) they do not get sexual satisfaction easily and hence look for other men to satisfy their sexual needs."- Key informant

Marriageability and complications during childbirth were often clubbed as reasons for FGM/C by participants. According to two young men, a young woman and female parents, there was a belief that the clitoris or the 'upper part' of the vagina would grow and gradually cover it. This was also mentioned as a cause of having difficulties during childbirth by young women (FGD, 15-24 years) and young men (FGD, 15-20 years).

"If clitoris is not removed, it is believed that females face severe labour and maternity complication because clitoris grow and cover the entire female genital organ." - FGD, Female Parent, Qewet

Many participants including young women, key informants, male parents, a grandmother and a young man mentioned instances where labour was harder for uncircumcised women. Hence, circumcisers, who had previously been dissuaded to continue this practice, were asked to return. However, one young woman (FGD, 20-24 years) shared her own experience of having a normal delivery despite being uncircumcised. This was supported by a key informant and a male religious leader who spoke about complications during pregnancy if a woman was circumcised.

Several participants mentioned that FGM/C would make women behave well, be cool, calm and not hot-tempered. Some participants such as a young man (IDI, 16 years), two young women (IDIs, 18 years and 24 years) and a grandmother used metaphors such as uncircumcised women would 'break utensils' to indicate this. As per two key informants, including one religious leader, an uncircumcised woman would be labeled as a woshela - someone having masculine traits.

Traditionally FGM/C was considered as the foundation of marriage and was meant to make the vagina 'clean' and smell good. A few participants indicated that an uncircumcised woman would have difficulty in urination. Other reasons for FGM/C included hygiene and maintaining purity. There seemed to be no links to religion which was confirmed by an Orthodox Christian religious leader. Most youth did not believe that their religion recommended FGM/C. Despite the presence of some dissenting voices such as from a religious leader in the community, people were largely convinced about the benefits of $\mathrm{FGM} / \mathrm{C}$.

There was quite some awareness regarding the harmful effects of FGM/C - and adverse effects on the woman's health was the most common. The awareness among young men was lower compared to that of other community members. In addition, a few young men, a key informant and a teacher felt that rates of FGM/C were declining faster than that of child marriage in the communities. A young man in an FGD (15-19) reasoned that once people became aware of the consequences of $\mathrm{FGM} / \mathrm{C}$ they readily gave it up. 


\section{Decision-making}

Due to the early age of undergoing $\mathrm{FGM} / \mathrm{C}$, many participants considered parental beliefs to be an important determinant of FGM/C. A few young women indicated that parents were the primary decision-makers on when a baby would be circumcised. As mentioned by two young men and a key informant, women - particularly mothers, played an important role in deciding. Extended family members such as grandmothers, aunts or paternal uncles would assist mothers in their decision and help with arrangements for the FGM/C. In only some case, fathers were involved. Young women were often cared by mothers during childbirth and hence fathers were unable to prevent FGM/C, according to a young man (IDI, 24 years). A young man (IDI, 16 years) elaborated that a father would take on a bigger role only if his daughter was considered misbehaved.

Most young people spoke of society's or others' beliefs, but it was not always clear what they themselves thought about FGM/C. Forty percent (40\%) of young women who reported being circumcised shared that they felt 'bad' about it. Some young women said that they knew of uncircumcised women who were able to marry and have children. Citing this example, they expressed that they would not wish to continue the practice on their daughters. As per the survey, $74 \%$ of the young women indicated that they would not circumcise their daughters due to various reasons - that it was illegal and not healthy. In contrast, those who did wish to do so cited cultural reasons as a motivator.

Giving birth at health centres was a deterrent for FGM/C. According to a young woman in an FGD (20-24 years), while delivering at the health centre, mothers were advised not to let their daughters undergo FGM/C. Several efforts were being taken by several government and NGO authorities to curb the practice and enforce the law. Moreover, religious leaders had mixed opinions regarding FGM/C. It was not clear whether these efforts and the role of religious leaders influenced people's decision-making.

\section{Case study Kenya}

\section{The act of FGM/C}

In Kenya, FGM/C was considered a social norm (60\%) and was primarily a traditional custom. It signified a transition from childhood to adulthood and was seen as a form of initiation. A few participants such as caregivers and a teacher indicated close to a $100 \%$ incidence rate of the practice in their community. However, our survey found that $52 \%$ of young women in Kajiado reported to be circumcised, indicating a possible gap between what was perceived in the community to what was actually practiced. While it is unlikely that young women would forget if they were cut, as FGM/C was done between 8 and 18 years of age, under-reporting may be possible as FGM/C is illegal. Although caregivers, youth, and a key informant mentioned that FGM/C was now done secretly, others such as a health worker said that attitudes were changing and FGM/C was considered optional.

Carried out during school holidays, young women (FGD, 19-24 years) shared that the practice included a cut treated with paraffin, sugar or cooking fat. According to a young woman (FGD, 15-17 years), circumcisers used gloves and scalpels at times, while some used injections to numb the body. Of those young women who reported to be circumcised, $30 \%$ stated they had a clitoredectomy[1] while $28 \%$ reported to have undergone an excision. Participants cited different ages of circumcision ranging from 8 to 18 years of age. According to a young woman (FGD, 15-17 years), in case one had an older sibling, it was likely that a young woman would be cut at the same time as their male or female sibling. There were a few accounts of uncircumcised women being cut at the time of their marriage and one account of being cut at the time of birth. Elderly women acted as circumcisers. Some study participants such as a key informant, a young woman (20 years) and a young man (21 years), were concerned about health risks: some of the circumcisers were not trained well enough or did not have enough experience. A young man (FGD, 18-24 years) revealed that at times, doctors were also complicit and would conduct FGM/C for a fee at the hospital in secret, or from home. 
"They are not taken to hospital because we all know that the government is against female circumcision, and so they are circumcised at home and celebrations are done later so as not to attract the attention of the government officials."- FGD, Female Caregiver

In the past, FGM/C was accompanied by a celebration, involving the family and community, often planned by older women without the girl's knowledge. A young woman (18-24 years, FGD) explained that the decision to cut would start at the family level, where a date would be set. The community would then fetch firewood and water and the girls and boys would be shaved in preparation. While some boys were taken to the hospital, girls were cut at home. According to a young boy (FGD, 15-17 years), if a celebration took place, it did so after a few months under the pretext of celebrating another event or as a celebration of male circumcision to allay suspicion. Hence, the act was not explicitly ceremonial anymore but was hidden.

\section{Reasons for FGM/C}

Reasons for FGM/C in the Maasai were wide-ranging. All participants including youth and community stakeholders shared that girls were considered women once they were circumcised. As explained by a health worker and young women, this meant that they were free to engage in sex without any restrictions and adult men could now approach these girls. As explained by a young woman in an FGD with females (15-17 years) "To be regarded as a woman, you have to be cut." The cut signified a transition from childhood to adulthood and one key informant framed it as a rite of passage. Many young women and a parent shared teenage pregnancies were common after FGM/C due to unprotected sex. Furthermore, in some cases, peer pressure played a role in the persistence of the practice as those girls who were uncut felt stigmatized.

"The girl disassociates herself with young girls and joins matured people, and thus, practicing all that a woman does. This leads to early pregnancy and then early marriage."-FGD, Chiefs

A few young women and men, a male caregiver and a key informant mentioned marriage and marriageability as a reason for FGM/C. This was referred to in two ways: one being that FGM/C would enable young women to find a good husband while the other, mentioned by a male caregiver, being that if not circumcised, young women would be cut before their wedding day. Fifty-four percent (54\%) of youth thought that FGM/C and child marriage were linked and $66 \%$ said it caused child marriage. However, two key informants emphasized that the link between marriage and FGM/C was simply a myth to instill fear in girls and that there were enough role model uncircumcised women who were happily married.

A parent and a young woman in an FGD (15-17 years) mentioned that FGM/C did not bring any benefits to young women. Only a young woman (FGD, 19-24 years) referred to FGM/C as a way to prevent itchiness and promote hygiene, while a teacher mentioned that those who did get circumcised were ill-mannered. A young woman (15-17 years) referred to FGM/C as a tradition.

FGM/C was also linked to pregnancy. According to a teacher and a caregiver (FGD), parents feared that their daughters would fall pregnant prior to circumcision which was considered taboo. Two young women (FGD, 15-24 years) shared that if women were not circumcised they would have difficulty during childbirth. Others, such as a key informant, health worker and a male caregiver, believed that undergoing FGM/C would cause difficulties in childbirth.

Almost all participants were aware about adverse health effects of FGM/C, particularly of immediate adverse effects such as excessive bleeding which could lead to death, difficulty in urinating and risk of infections due to unsterilized razor blades. Only one young woman (FGD, 19-24 years) mentioned lack of sexual feeling while a male caregiver mentioned lower libido as a result of FGM/C.

\section{Decision-making}


Many study participants shared that both mother and father decided if their daughter was to be circumcised. Some participants cited the father as the main decision-maker, while others shared that it was the mother. According to one key informant, fathers would get involved when girls refused to undergo FGM/C, whereas another key informant shared that fathers often agreed with the law and did not opt for FGM/C. In some cases, grandmothers would intervene to ensure $\mathrm{FGM} / \mathrm{C}$ was carried out. Even if one parent did not agree to $\mathrm{FGM} / \mathrm{C}$, the other parent could organize it secretly. According to a young woman in an FGD (15-17 years), parents' decision to circumcise also depended on their literacy levels. The survey data show that $88 \%$ of young women indicated that they would not circumcise their daughters, however, this could be a result of respondents giving socially desirable answers.

A key informant shared that there were a few parents who asked the girl for her opinion on FGM/C. Male caregivers, young women and a key informant shared that many young women chose to be circumcised due to the perceived social benefits of FGM/C. However, a policy-maker emphasized that many of these girls were too young to make informed choices and were often influenced by their mothers regarding FGM/C. Moreover, key informants, a health worker and a young women mentioned that some girls were forced to undergo the cut despite refusing. The survey found that girls had mixed feelings about being circumcised. Of the girls who reported to be circumcised, $56 \%$ reported to feel bad about it while $32 \%$ reported to feel good. Among those who felt bad about it, $30 \%$ had their FGM/C done secretly and not in the form of a celebration ceremony. Many who did not feel bad about it said that they volunteered to be cut due to either peer pressure or to feel a stronger sense of belonging with their peers and community.

\section{Footnote:}

[1] Two types of clitoredectomy are practiced by the Maasai. The survey did not provide differentiated answers.

\section{Discussion}

The first part of the discussion deliberates on the findings from each setting - the different ways in which FGM/C is framed, followed by a discussion on how agency manifests and on what role the body plays in reproducing social and gender norms.

\section{Different frames of FGM/C}

In Indonesia, the reasons to circumcise are inter-connected, where religion intertwines with tradition and the control of woman's sexuality (18). Participants' interpretations of Islam frame women's sexuality as insatiable and therefore dangerous. Alongside, the need for cleanliness or removing najis or impurities and 'cleaning the dirt' is also found by $(5,8)$ and is the government's discourse on FGM/C, evident from a regulation passed in 2010 (19). Hence, the measures taken through sunat or what is called 'female circumcision' in Indonesia are deemed as a purification ritual (5). The natural state of the body at birth is considered impure and is physically manipulated to become pure (20). This results in a 'pure body' pure in its (limited) sexual drive and clean.

In Ethiopia, the "cultural logic of circumcision are both related to subordination of women..... and...control of reproductive capacity" (11). This includes sexual performance for reproductive purposes, women's ability to give birth and their marriageability - partly defined by their temperament and behaviour $(11,13)$. FGM/C is believed to promote sexual compatibility $(11,14)$ and prevent difficulty while giving birth $(11)$. We found that in some cases if a young woman is not circumcised at birth, she may be prior to her marriage. FGM/C becomes a strategy to ensure good, submissive and obedient wives. Beliefs around the growth of an uncut clitoris, and difficulty penetrating an uncut woman further reinforce misconceptions about women's bodies. In Ethiopia, FGM/C transforms the to-be woman into a 'tame' body - tame with regard to sexual desire and being obedient.

In Kenya, among the Maasai, the cut symbolizes a transition from childhood to womanhood and a readiness for marriage (21). However, as per our findings, womanhood primarily takes form of sanctioning sexual activity as opposed to marriage.

Page $10 / 15$ 
This 'becoming of a woman' results in an 'adult body' where young girls can behave like adult women. This resonates with Njambi's own experience as a Kikuyu where she was considered a child and not allowed to join adult conversations on menstrual cycles, pregnancy and sex prior to her circumcision (22). Tammary et al. (2013) states that for the Maasai, the cut legitimizes sexual relations and having a pregnancy before undergoing FGM/C is taboo (21). While FGM/C aims to reduce young women's sexuality in Indonesia and Ethiopia, it functions as a signal for young woman in Kenya to explore their sexuality.

\section{The cultured body}

FGM/C drives certain ideals about what a woman should be like and their bodies become the medium through which these beliefs are exercised. Body markings such as the cutting of the clitoris are used to construct, shape and perform social and gender identities (as suggested by $(21,23,24)$ ). The body in its natural state at birth is "unappealing" and "misshapen" and must be transformed to be "smooth, cleansed and refined" (25). The body has always been at the centre-stage of the social (26) and becomes a site of contestation, subversion or resistance (27). FGM/C modifies and shapes the woman (through her body) to be a certain type of 'feminine'. These beliefs result in the production of a the holy/pure body in Indonesia, 'cultured body', of a tame body in Ethiopia, the adult body in Kenya and, which many young women aspire to.

\section{Navigating agency}

The cultured body shuttles between being an active or passive agent in the act of FGM/C. If agency is understood as being possessed by a physical body, it does not lie with the body that is being acted upon. It is extended to those that are caretakers of the body - i.e. most often family members in all three countries. Parents, particularly mothers, play a crucial role in all three settings $(6,13,14,21)$. Involving fathers more also can act as a protective strategy for reducing FGM/C (28).

The pervasive prevalence of circumcision in Indonesia, its commonplace offering in paraji's 'birth packages', and the neutral attitudes expressed by circumcised women regarding their own FGM/C demonstrates the normalcy of the practice (29). This could be linked to the early age of cutting and the 'light' version of FGM/C practiced there (18). This explains why a majority of young women wished to circumcise their daughters in the future. In contrast, in Ethiopia, where the age of cutting is also very low, young women had clearer opinions opposing this, as they were aware of adverse consequences which could be higher due to the type of FGM/C. This was also true in Kenya. This opinion could reflect the higher levels of awareness regarding the law in both countries as well as stronger campaigning.

In Kenya, since young women are older at the time of FGM/C, they play somewhat of an active role - in either resisting, accepting or wanting to be circumcised. FGM/C offers women an opportunity, legitimacy and power to engage with their larger male dominated community $(22,25,30)$ and allows Maasai women to negotiate their gender, identity and sexuality $(17,21)$. However, we must be cautious in understanding women's agency in this context, as our survey results show a sizeable percentage of women who felt 'bad' upon being cut.

\section{Changing contexts and changing tradition}

In Indonesia, the study found FGM/C of Type 1 and Type 4, ranging from a cut to a symbolic cutting of turmeric. This confirms Clarence-Smith's (2008) findings that Female Genital Cutting of the South-east Asian type does not involve deep or major cuts or removal of flesh (31). However, the reasons for circumcision given by South East Asian Muslims are that it marks a woman's full initiation into Islam, which does not match the reasons found by this study which are linked to Islam, tradition, hygiene and a control of sexuality. Feillard and Marcoes (1998) found that in Sukabumi, a knife was used (without any bleeding) for the FGM/C (32). In comparison, our findings suggest that there is some change in the tools used which could be due to the medicalization of the practice, as also found by (9). Moreover, this medicalization could also have led to FGM/C not being ceremonial anymore, found by our study as well. Some scholars argue that rising Islamic fundamentalism combined with government's drive for medicalization for harm reduction (33) has resulted in 'real cutting' 
which is replacing the symbolic type $(6,9)$. However, our study finds that some health workers were refusing to perform FGM/C or 'pretending' to do so by doing a symbolic form to placate parents. At the same time, other health workers did not offer FGM/C as they recognized the health risks. Similarly, Putranti (2008) found that different types of circumcision carried out by both traditional circumcisers and health practitioners co-existed in the same areas, with the latter performing FGM/C in a way that no actual cut was made (9).

Strong social norms overpower the change that is being attempted by the law in the Ethiopian context, which Boyden et al. (2013) frame as resistance and counter-reactions (11). There are government campaigns and activities that are widely present in the country (11) which may explain the high levels of awareness about FGM/C being illegal. The government stance on criminalizing the practice seems to have driven it underground and due to this, it is unclear how many young women are cut. Comparative surveys available indicate a decline in rates of FGM/C (11). Although not directly comparable, our findings indicate a lower prevalence of $\mathrm{FGM} / \mathrm{C}$ as compared to the nation-wide statistic of $92 \%$ of young women (1549) (34) and the Amhara-wide statistics of $47 \%$ among girls under 15 (35).

In Kenya, our finding that FGM/C was not publicly celebrated anymore due to its criminalization was also found by Esho et al. 2011 (36). The Kenya DHS found that circumcision takes place between the ages of 12 and 14 years, while our findings indicate a larger age range; it could occur as early as eight years. In this vein, an analysis of Kenyan DHS data indicates that age of circumcision is falling $(16,37)$. As per Herlund et al. 2000 as cited in Shell-Duncan, Naik and Feldman-Jacobs (2016), this decline could be influenced by communities wanting to avoid detection due to the criminalization (38)(38-40). Girls of younger ages also find it harder to resist and heal quicker (41). This lowering of age is particularly alarming, as girls and young women explicitly pursued the idea of becoming a woman and engaging in (unprotected) sexual behavior through FGM/C, often resulting in teenage pregnancy which led to (child) marriage. Moreover, other studies have found that there is increased medicalization of FGM/C in Kenya which should be further explored among the Maasai (42).

\section{Conclusions}

The study concludes that there is variation in the practice of $\mathrm{FGM} / \mathrm{C}$ and that there are multiple inter-connected reasons for FGM/C in each setting. These are driven by unequal gender norms and dictate how young women must embody specific characteristics and perform traditional roles to fulfill their femininities. The female body is the medium through which these norms are negotiated and fulfilled and its 'natural' form is modified through FGM/C and transformed into a 'cultural body'. The agency of parents must be further explored. In Ethiopia and Kenya, our findings suggest that the cost of abandonment may be too high and community-wide public pledges may make a difference in reducing FGM/C rates (3). In Indonesia, campaigning must begin by problematizing FGM/C. In Kenya and Ethiopia, FGM/C persists despite having a law criminalizing FGM/C to different extents. The variation in the practice and multiplicity of drivers in each setting imply that context-specific interventions are needed. Although body markings are common in communities, interventions promoting medicalization or symbolic forms are still a violation of women's rights.

\section{List Of Abbreviations}

FGM/C- Female Genital Mutilation/Cutting

IDI- In-depth Interview

KII- Key Informant Interview

FGD- Focus Group Discussion

TBA-Traditional birth Attendant

DHS- Demographic Health Survey

Page 12/15 


\section{Declarations}

Ethics approval and consent to participate: Ethical approval was granted from the KIT Royal Tropical Research Ethics Committee and the Research Ethics Committee of the Faculty of Public Health, University of Indonesia, Ethical Review Committee of the Amhara Region Public Health Institute in Ethiopia and the African Medical and Research Foundation (AMREF) in Kenya. Informed written consent was given by the study participants. Consent was given by parents or caregivers for participants under the age of 18.

Consent for publication: Not applicable.

Availability of data and materials: The datasets used and/or analysed during the current study are available from the corresponding author on reasonable request.

Competing interests: The authors declare that they have no competing interests.

Funding: This study was part of the Yes I Do programme, funded by the Dutch Ministry of Foreign Affairs SRHR Partnership Fund (2016-2020).

Authors' contributions: MK, AvdK, IH, BA, TG conceptualized the study design. IH, BA, TG led the data collection. TK conducted the analysis. TK wrote the first draft of the article. IH, BA, TG, MK and AvdK critically reviewed the manuscript. All authors read and approved the final manuscript.

Acknowledgements: The authors would like to acknowledge the contributions of the research assistants and supervisors at baseline and end-line. The authors would also like to acknowledge the contribution of Claribel Nkansah. The authors thank the study respondents and participants in all countries.

\section{Authors' information (optional)}

a KIT Royal Tropical Institute, Amsterdam, The Netherlands

b Center for Gender and Sexuality Studies, Universitas Indonesia

${ }^{\mathrm{c}}$ Addis Ababa University, Ethiopia

d Independent Consultant, Kenya

e KIT Royal Tropical Institute, Amsterdam, The Netherlands

${ }^{f}$ KIT Royal Tropical Institute, Amsterdam, The Netherlands

\section{References}

1. UNFPA. Female genital mutilation (FGM) frequently asked questions [Internet]. 2020. Available from: https://www.unfpa.org/resources/female-genital-mutilation-fgm-frequently-asked-questions.

2. Berg RC, Denison E. Health Care for Women International A Tradition in Transition: Factors Perpetuating and Hindering the Continuance of Female Genital Mutilation / Cutting (FGM / C) Summarized in a Systematic Review A Tradition in Transition : Factors Perpetuating Genita. 2013;9332(October 2017).

3. Mackie G. ENDING FOOTBINDING AND INFIBULATION: A CONVENTION ACCOUNT *. 1996;61(6):999-1017.

4. UNICEF. Statistical profile on female genital mutilation/cutting in Indonesia. 2019. 
5. Newland L. Female circumcision: Muslim identities and zero tolerance policies in rural West Java. 2006;29:394-404.

6. Budiharsana M, Amaliah L, Utomo B. Female Circumcision in Indonesia. 2003;(September).

7. Imelda JD, Kartikawati R, Mahendro AY, Ratri SD. Elimination of Female Genital Circumcision in Indonesian Transition Society: Revealing a Hope. 2018;2018(Icspi 2016):427-43.

8. Putranti BD, Faturochman, Darwin M, Purwatiningsih S. Male and female genital cutting among Javanese and Madurese. 2003.

9. Putranti BD. To, Islamize, Becoming a Real Woman or Commercialized Practices? Questioning Female Genital Cutting in Indonesia. Finnish J Ethn Migratio [Internet]. 2008;23-31. Available from:

http://web.a.ebscohost.com/ehost/detail/detail?vid=10\&sid=225d73b0-a977-46e7-994e-

121730a27a30\%40sessionmgr4003\&hid=4214\&bdata=JnNpdGU9ZWhvc3QtbGI2ZQ\%3D\%3D\#AN=35693959\&db=sih.

10. 28toomany. FGM IN ETHIOPIA. 2013;(October).

11. Boyden J, Pankhurst A, Tafere Y. Harmful Traditional Practices and Child Protection: 2013.

12. Tamire M, Molla M. Prevalence and belief in the continuation of female genital cutting among high school girls: a cross - sectional study in Hadiya zone, Southern. 2013.

13. Bogale D, Markos D, Kaso M. Prevalence of female genital mutilation and its effect on women 's health in Bale zone, Ethiopia : a cross-sectional study. 2014;1-10.

14. Gebremariam K, Assefa DWF. Prevalence and associated factors of female genital cutting among adult females in Jigjiga district, eastern Ethiopia : a cross-sectional mixed study. 2016;357-65.

15. Yirga SW, Kassa AN, Welday M, Aro G RA. Female genital mutilation: prevalence, perceptions and effect on women 's health in Kersa district of Ethiopia. 2012;65504283:45-54.

16. Kenya National Bureau of Statistics; Ministry of Health/Kenya; National AIDS Control Council/Kenya; Kenya Medical Research Institute; National Council for Population and Development/Kenya. Kenya Demographic and Health Survey 2014. 2015.

17. Esho T, Enzlin P, van Wolputte S, Temmerman M. Female genital cutting and sexual function: In search of an alternate theoretical model. African Identities. 2010;8(3):221-35.

18. Octavia L. Circumcision and Muslim Women's Identity in Indonesia. Indones J Islam Stud. 2014;21(3):419-57.

19. Hidayana IM, Djamilah IJ, Kartikawati R, Az Zahro F. Female circumcision in Indonesia: Between Policy and Practice. In: FGM/C: From Medicine to Critical Anthropology. Meti Edizioni; 2018. pp. 95-106.

20. Finke E. Genital mutilation as an expression of power structures: ending FGM through education, empowerment of women and removal of taboos. Afr J Reprod Health. 2006;10(2):13-7.

21. Tammary E, Enzlin P, Van Wolputte S. BORDERS OF THE PRESENT: MAASAI TRADI- TION, MODERNITY, AND FEMALE IDENTITY. 2013;(March 2015).

22. Njambi WN. Dualisms and female bodies in representations of African female circumcision: A feminist critique. Fem Theory. 2004;5(3):281-303.

23. Kwaak AVANDER. FEMALE CIRCUMCISION AND, GENDER IDENTITY:. QUESTIONABLE ALLIANCE ? 1992;35(6).

24. Butler J. Acts and Gender Performative An Essay in Phenomenology Constitution: and Feminist Theory. 1988;40(4):519-31.

25. Shweder R. What About " Female Genital Mutilation ? And Why Understanding Culture Matters in the First Place. 2000;129(4):209-32.

26. Langman L, Culture, Identity and Hegemony: The Body in a Global Age. 2003;51(July):223-47.

27. Grosz E. Bodies and Knowledges: Feminism and the crisis of reason. In: Feminist Epistemologies. 1993. p. 187-216.

28. Mwendwa P, Mutea N, Kaimuri MJ, De Brún A, Kroll T. "Promote locally led initiatives to fight female genital mutilation/cutting (FGM/C)" lessons from anti-FGM/C advocates in rural Kenya. Reprod Health. 2020;17(1):1-15.

Page $14 / 15$ 
29. Ida R, Saud M. Female Circumcision and the Construction of Female Sexuality: A Study on Madurese in Indonesia. Sex Cult [Internet]. 2020;24(6):1987-2006. Available from: https://doi.org/10.1007/s12119-020-09732-6.

30. Gruenbaum E. The Female Circumcision Controversy: An Anthropological Perspectivel. University of Pennsylvania Press; 2001.

31. Clarence-Smith WG. Islam and Female Genital Cutting in Southeast Asia: The Weight of the Past. Finnish J Ethn Migr. 2008;3(No.2):14-22.

32. Feillard A, Marcoes L. Female Circumcision in Indonesia: To " Islamize " in Ceremony or Secrecy. 1998;56(Volume I):337-67.

33. Leye E, Van Eekert N, Shamu S, Esho T, Barrett H. Debating medicalization of Female Genital Mutilation/Cutting (FGM/C): Learning from (policy) experiences across countries. Reprod Health. 2019;16(1):1-10.

34. Central Statistical Agency/CSA/Ethiopia and ICF. Ethiopia Demographic and Health Survey 2016. 2016.

35. Central Statistical Agency. Welfare Monitoring Survey. 2011. Stat Bull [Internet]. 2012;(April):1-632. Available from: http://www.csa.gov.et/index.php/2013-02-20-13-43-35/2013-02-20-13-45-32/welfare-monitoring-survey/2010-gc.

36. Esho T, Wolputte $S$, Van, Enzlin P. The socio-cultural-symbolic nexus in the perpetuation of female genital cutting: a critical review of existing discourses. 2011;24(2):53-70.

37. Shell-duncan B, Moore Z, Njue C. the Medicalization of Female. 2017;(February).

38. 28TooMany. Kenya: Country Profile Update. 2016;(December). Available from:

http://28toomany.org/media/file/profile/Kenya_Update_FINAL_COMPRESSED.pdf.

39. Shell-Duncan B, Naik R, Feldman-Jacobs C. A State-of-the-art synthesis of female gential mutilation/cutting: what do we know now? Popul Counc Inc. 2016;2016(October):1-30.

40. Hernlund Y. Cutting without ritual and ritual without cutting: Female "circumcision" and the re-ritualization of initiation in The Gambia. In: Shell-Duncan B, Hernlund Y, editors. Female “Circumcision” in Africa: Culture, Controversy, and Change. Lynne Rienner Publishers; 2000.

41. Njue C. Medicalization of Female Genital Cutting Among the Abagusii in Nyanza Province, Kenya. 2004;(December).

42. Population Council. Evidence the Medicalisation of Female Genital Mutilation / Cutting in Kenya. Perspectives of Families and Health Care Providers; 2019.

\section{Supplementary Files}

This is a list of supplementary files associated with this preprint. Click to download.

- Additionalfile3SRQRChecklist.pdf

- Additionalfile1.pdf

- Additionalfile2.pdf 